\title{
CONTRIBUIÇÕES DO LÚDICO NO DESENVOLVIMENTO DA CRIANÇA COM TRANSTORNO DO ESPECTRO DO AUTISMO
}

Rúdia Vieira dos Santos

Prof. Centro Universitário

\section{RESUMO}

Este artigo visa compreender a importância da utilização do lúdico como ferramenta metodológica na aquisição do saber no processo ensino-aprendizagem de crianças com autismo. Diante disso, no processo educacional inserir o uso da ludicidade como um instrumento de ampliação dos recursos metodológicos do professor integrando a prática pedagógica como elemento facilitador no ensino do aluno com necessidades educacionais específicas. A ideia principal é contribuir mediante as práticas lúdicas para o desenvolvimento das habilidades e potencialidades da criança com transtorno do espectro do autismo. Neste sentido, a atividade lúdica conduz o autista a experienciar formas diferentes de aprender, de ser e de pensar, como também, ampliar suas percepções sobre pessoas e objetos. Esta obra possui informações pertinentes para compreensão do professor, visto que, é importante respeitar o tempo e a singularidade de cada autista, acentua a relevância de propiciar formas diferentes de ensinar com a devida intervenção didática. A pesquisa aborda as concepções através dos referenciais teóricos como Vygotsky e Piaget e entre outros.

Palavras-Chave: Autismo, Lúdico, Desenvolvimento, Ensino-Aprendizagem 


\section{ABSTRACT}

This article aims to explain the importance of using playfulness as a methodological tool in the teaching-learning process of children with autism. Therefore, in the educational process the use of playfulness is an instrument to expand the methodological resources of the teacher, integrating pedagogical practice as a facilitating element in the teaching of students with specific educational needs. The main idea is to contribute through playful practices to the development of the skills and potential of the child with autism spectrum disorder. In this sense, ludic activity leads the autistic individual to try different ways of learning in regards to their behavior and thought process as well as expanding their perceptions about people and objects. This article has relevant information for the understanding of the teacher and highlights the importance of uniqueness of each autistic person. It emphasizes the relevance of providing different ways of teaching with the appropriate didactic intervention. The research approaches the conceptions through the theoretical references such as Vygotsky and Piaget books.

\section{Key-words: Autism - Playful - Development - Teaching-learning}

\section{1- INTRODUÇÃO}

O artigo está inserido na área da educação Inclusiva e visa apresentar relevante contribuição pela utilização do lúdico como recurso pedagógico no processo de desenvolvimento ensino-aprendizagem do educando com autismo. Portanto, uma educação engajada com a inserção do autista no contexto educacional respeita suas particularidades ao observar os moldes de comportamento apresentado pela criança autista, incentiva interação social e oportuniza por meio de estratégias lúdicas o desenvolvimento de suas habilidades e potencialidades.

Tendo em vista essas informações, a utilização do lúdico como estratégia pedagógica tem seu papel significativo na construção do saber, onde possibilita a criança com transtorno do espectro do autismo aprendizagem por meio de símbolos, o que facilita seu desenvolvimento cognitivo. Em contrapartida, os docentes possuem uma visão deturpada referente o lúdico que acaba por muitas vezes sendo um mero "Brincar", fora do contexto e sem atribuir significado específico, dificultando assim, sua utilização como ferramenta metodológica. Neste sentido, o objetivo do estudo é apresentar a real importância do lúdico no desenvolvimento de potencialidades e habilidades no processo de aquisição do conhecimento do discente com autismo. 
O educador antes de inserir no contexto educacional a proposta lúdica por meio do uso dos brinquedos, jogos e materiais pedagógicos, precisa anteriormente a este processo identificar a matriz simbólica do objeto, assim fica fácil compreender as necessidades $e$ dificuldades dos educandos (Kishimoto, 2011, p. 13).

Os capítulos estão estruturados de forma que envolva o leitor a mergulhar no universo do Autismo. Desta forma, o primeiro capítulo é uma breve revisão bibliográfica está organizada em períodos, trata-se dos primórdios sobre o autismo, menciona os principais pesquisadores empíricos que nos permite um relevante conhecimento referente o comportamento dos autistas. O próximo capítulo descreve o lúdico, e dentro desse universo temos o brincar e as brincadeiras que planejadas e organizadas são utilizadas como recurso pedagógico auxiliando no processo de ensino-aprendizagem. 0 último capítulo aponta uma práxis pedagógica que respeita a singularidade do autista, demonstra atividades lúdicas aplicáveis que estimuladas e repetitivas convertem-se estratégias metodológicas facilitadoras no decorrer do processo educacional.

A pesquisa científica apoderou-se das concepções teóricas de Jean Piaget (1980) e Vygotsky (1994), concepções de como se dá o desenvolvimento intelectual dos humanos, temos também importante contribuição do doutor e professor Antônio Eugênio Cunha (2018) especificamente sobre o desenvolvimento intelectual dentro do contexto dos estágios de aprendizagem do autista. Experiências que levaram os pensadores analisar e entender como são desenvolvidas as estruturas do funcionamento da mente humana.

A proposta desta pesquisa bibliográfica é fornecer subsídio para o docente apropriar-se das técnicas do lúdico e dinamizar o trabalho pedagógico, assim favorecer a criança autista um aprendizado aprazível.

\section{2- REFERENCIAL TEÓRICO}

\section{2-1 O PROCESSO EVOLUTIVO DO CONCEITO DE AUTISMO}

Para Donvan (2017, p.13) a história do autismo se constitui sobre muitas outras histórias que acontecem em diferentes países. No tocante em relação aos primórdios da história do autismo pode-se constatar a crueldade e o abandono que marcou muitas crianças autistas.

O suíço Eugene Bleuler, em 1911, introduziu o termo "Autismo" na literatura médica onde trabalhava com um grupo de pessoas com sintomas psicóticos e esquizofrênicos, para descrever pessoas com grande dificuldade de interagir uma com as outras pessoas e com muita tendência ao isolamento. (Camargo, 2010)

O psiquiatra Leo Kanner, em 1943, publicou o artigo "Distúrbios Autísticos do Contato Afetivo", estudos realizados em onze crianças que tinham em comum um isolamento 
extremo desde o início da vida e um desejo obsessivo pela preservação de rotina, denominadas "autistas" utilizando o termo "autismo infantil precoce", foi observado que as manifestações comportamentais surgiam na infância. Estas crianças apresentavam os seguintes sintomas: extrema solidão, incapacidade para se relacionar com as pessoas e alterações de linguagem e comunicação muito severas, tanto no plano expressivo como no receptivo. Kanner contextualiza essas observações no desenvolvimento, assim como enfatiza a predominância dos déficits de relacionamento social e comportamentos incomuns (Camargos, 2010).

Ao prestar atendimento pedagógico terapêutico para crianças autistas, em 1944, o doutor Hans Asperger junto com a equipe da Clínica Universitária de Viena no Departamento de Pedagogia Terapêutica (Heipadagogische Abteilung), publicou o artigo "Psicopatia autista na Infância". Definiu Asperger - "O transtorno fundamental dos autistas é a limitação de suas relações sociais. O efeito negativo consiste em comprometer a formação da personalidade destas crianças que está determinada por essa limitação". O autismo pela complexidade de seu comportamento era considerado um transtorno de personalidade e desafiava a Educação Especial, por questionar-se, quais estímulos deveriam ser elaborado para educar intelectualmente uma criança autista? (Gómez, 2014, p. 462 e 463).

Os médicos Kanner e Asperger realizaram suas pesquisas isoladamente, ainda assim, as características atribuídas ao comportamento social do autismo assemelham-se, porém, as abordagens dadas aos autistas diferenciam-se, a investigação empírica de Asperger direciona suas percepções à Educação mediante a pedagogia terapêutica junto com desenvolvimento biológico, enquanto Kanner preocupou-se apenas com o biológico. Os psiquiatras cada um em seu país desenvolvem suas pesquisas atribuindo os sintomas da síndrome que atualmente denominamos Transtorno do Espectro do Autismo (TEA).

\section{2-2 ENFOQUE SOBRE AUTISMO NOS PERÍODOS ENTRE 1943 À 1963.}

Vista em retrospecto, os primeiros 20 anos de estudos e métodos, sobre o autismo, inicialmente observados, como um transtorno emocional ou afetivo, desencadeado por distúrbios emocionais ou afetivos na relação inadequada dos pais para com seus filhos, distúrbios esses que não contribuem para o desenvolvimento da personalidade da criança. De acordo com Donvan (2017), o veredito constatado pela psiquiatria do final da década de 1940, foi: o autismo era causado por mães que não amavam suficiente seu(s) filho(s), por isso, que algumas crianças poderiam ser autistas e outras não. Nesta concepção, mães/pais incapazes de proporcionar o carinho necessário há seus filhos resultaria na paralização do desenvolvimento da criança que seria potencialmente normal e que poderia ter inteligência muito melhor do que apresentada, no entanto não demonstrava por causa da perturbação emocional e características negativas da criação. Neste período o tratamento dado aos autistas era Terapia Dinâmica que reestruturava 
os laços emocionais afetivos, sendo o mecanismo da época para melhor ajudar a criança autista (Coll, 2004, p. 236).

No decorrer desses vinte anos fora elaborado concepções sobre a síndrome do autismo até tornar-se ultrapassadas, contudo, introduziu na literatura relevante contribuição devido o conhecimento que norteia as pesquisas subsequentes. Neste período, nega-se afirmação dada que o autismo seja uma síndrome desencadeada por transtornos emocionais, os estudos empíricos não conseguem evidenciar que os pais sejam responsáveis pelo disfuncionamento no desenvolvimento de seus filhos, descobriu-se que a causa poderia ser biológica junto com atraso mental. Conclusão deste período, as terapias dinâmicas não apresentaram eficácia no tratamento do autismo, pelo contrário, os resultados satisfatórios obtidos foram pelo engajamento da Educação.

\section{2-3 ENFOQUE SOBRE AUTISMO NOS PERÍODOS ENTRE 1963 À 1983.}

No início da década de 60, a concepção referente a falta de amorosidade por parte dos pais fora eliminada pelo motivo de não haver justificativa empírica e novos estudos modificam a visão científica e o tratamento dado ao autista, pois na segunda metade da década, os primeiros indícios do autismo associados aos transtornos neurobiológicos passam a ter importância (Gómez, 2014, p. 467).

De acordo com GÓMEZ (2014), em 1970, surgem às teorias cognitivas e mudanças no comportamento da criança autista, a partir daí a investigação e intervenção passa a ser de forma controlada e sistematizadora. Foram elaborados modelos explicativos para fundamentar a hipótese da existência de alteração cognitiva em relação ao afeto, determinante para explicar as manifestações da síndrome, tais como: inabilidade de interação, linguagem, comunicação e flexibilidade mental. As teorias cognitivas contribuem na fundação de Centros Educativos e Associações de Pais objetivando qualificar o atendimento e melhorar a interação do autista e seus familiares.

Nos anos 60, 70 e 80, a Educação torna-se o principal tratamento para crianças e adultos autistas, a educação foi sistematizada para melhor atender e intervir no desenvolvimento de procedimentos para modificação comportamental e na criação de centros educacionais específicos dedicados ao autismo.

Gómez (2014) afirma que, a partir da segunda metade dos anos 80 que o autismo passa a ser investigado pelo desenvolvimento dos mecanismos cognitivos e motivacionais, contudo, retrocede a concepção das manifestações do desenvolvimento social e interacional, diferenciando os autistas pelas características comportamentais, tais como:

- Dificuldade ao interagir com crianças e adultos;

- Dificuldade em atender seus próprios comportamentos ao compartilhar experiências com as demais pessoas. 
- Dificuldade de reagir mediante as atitudes das demais pessoas em demonstrar medo e desconforto na presença do autista;

- Dificuldade em intervir em questões sociais;

- Dificuldade no processamento perceptivo e psicomotor;

- Dificuldade em imitar ações e atitudes;

- Dificuldade no processo de desenvolvimento do "afeto" às pessoas que acontece de forma natural na consciência de si e dos outros (GÓMEZ, 2014, p. 467 e 468).

Estas características mencionadas à cima são encontradas em outros transtornos do desenvolvimento, porém é mais significativa para o autista. Dessa forma, as dificuldades causam distúrbios no desenvolvimento das áreas de interação, comunicação, desenvolvimento social, disfunções cognitivas, perceptivas e motoras.

\section{2-4 ENFOQUE SOBRE AUTISMO NA ATUALIDADE.}

Podemos observar que o autismo é uma síndrome que atribui inúmeras causas, atualmente são determinantes os estudos cuja pesquisa tem focado na psicologia evolutiva, verifica-se que as questões diagnosticadas na psicopatia, como à psicose infantil tem sido substituída pelo transtorno global do desenvolvimento (COLL, 2004, p. 237).

É notório identificar as alterações que acontecem para explicar o Autismo nos aspectos psicológico e neurobiológico, os moldes e as teorias das décadas de 60 e 70 contribuíram com seus dados, mesmo sendo pouco. O autor COLL (2004), menciona que na década de 80 os neurobiólogos e pesquisadores Baron-Cohen, Leslie e Frith, intitulam a "teoria da mente" justamente para especificar uma anomalia dos autistas, caracterizada por um transtorno de incapacidade humana. Os avanços nos estudos da genética, neuroquímica, exploração citológica, neuroimagem, eletrofisiologia, são significativos e revela um novo panorama, os dados mostram alterações importantes que se aproxima das prováveis causas do autismo.

Ao longo das últimas décadas obtivemos a complexa questão sobre o autismo e o tratamento oferecido ao autista, contudo, nota-se acentuada contribuição obtida pela Educação que demonstrou ser mais pragmática e intrínseca, partindo da comunicação como ponto central do desenvolvimento, mesmo sabendo das dificuldades, ainda assim, respeitando a capacidade singular de cada indivíduo. O educador primordialmente deve conhecer seu aluno autista, deve-se analisar o nível de desenvolvimento cognitivo do autista, na sequência planejar os trabalhos pedagógicos partindo da realidade da criança autista, pois ele é o protagonista, neste contexto educacional proporcionar estímulos lúdicos significativos.

\section{3- LÚDICO}

O lúdico tornou-se indispensável, de forma que deixou de ser apenas "jogo", transformando-se em contribuições por intermédio das práticas lúdicas, dando a elas 
um cunho pedagógico. De acordo com Rappaport (apud Almeida, 1987), todos os sujeitos deficientes percebem, aprendem, pensam e se adaptam de modo fundamentalmente idêntico ao dos demais. Neste contexto, todos nós percebemos, pensamos, aprendemos e nos adaptamos, tanto pessoal como socialmente, em conformidade com os mesmos princípios e regras gerais, mesmo o indivíduo possuindo ou não qualquer deficiência física, mental ou socioemocional. No entanto, alguns indivíduos fazem isto de maneira eficiente e rápida, enquanto outros o fazem mais lento e menos eficiente.

Mediante as atividades lúdicas a criança assimila valores, adquire comportamentos, desenvolve diversas áreas do conhecimento, exercitase fisicamente e aperfeiçoa habilidades motoras. Este aprendizado enquadra o educando com autismo, sendo o protagonista de seu conhecimento, todavia, cabe ao docente afetuosamente proporcionar as atividades pedagógicas com formato diferenciado (CUNHA, 2018, p. 15).

Quando o lúdico é significativo à adição dos brinquedos e dos jogos são introduzidos de maneira prazerosa e facilitadora no processo educacional, no desenvolvimento ocorre um relevante aprimoramento nas habilidades motoras, físicas, intelectuais e morais da criança e no seu reconhecimento como indivíduo pertencente ao âmbito escolar. Cunha (2018), afirma que o aluno autista mesmo com extrema dificuldade de comunicação, com visível déficit de atenção, hiperativo e apresentando atrasos cognitivos e motores, um autêntico autista clássico, ainda assim, aprende e ao receber afeto do professor o resultado foi de crianças autistas providas de curiosidades que desenvolvem seus interesses peculiares.

É possível afirmar que a ludicidade deve estar presente no cotidiano do educando, partindo de uma educação que constrói na criança o melhor modo de se portar para saciar suas necessidades de entender, produzir, observar, brincar, trabalhar e viver. 0 lúdico é considerado um meio de divertimento, pois proporciona ao aluno uma facilidade maior em aprender, do mesmo modo, como a construção do conhecimento e o desenvolvimento na comunicação. Segundo Almeida (1987), por meio da brincadeira a criança envolve-se no jogo e sente a necessidade de partilhar com o outro. Mesmo que a conduta seja de adversário, a parceria é estabelecida por relação, esta relação manifesta as potencialidades dos participantes, afeta as emoções e põe à prova as aptidões testando limites. Brincando e jogando a criança terá oportunidade de desenvolver capacidades inatas ou não indispensáveis a sua formação. Brincando a criança mostra-se operante.

Segundo Kishimoto (2009), abordar a perspectiva piagetiana que compreende a brincadeira como ação assimiladora, a brincadeira apresenta-se na forma de expressão da conduta, dotada de característica metafórica como espontânea e prazerosa. Deste modo, pode-se refletir que a brincadeira possui um lugar fundamental no 
desenvolvimento de toda criança, pois fornece a criança um ambiente planejado de várias atividades, além disso, está ligada ao seu aspecto do desenvolvimento físico, cognitivo e afetivo.

É importante que o docente viabilize outros recursos metodológicos para ensinar, desde que, reflita se a prática pedagógica lúdica envolvendo o jogo encontra-se de acordo com as aprendizagens da criança autista. Cabe ao professor mensurar as relações cognitivas do educando autista mediante os desafios que atividade oferecer, necessária compreensão dos aspectos relacionados à função simbólica, como também, analisar conteúdos que desperte o interesse afetivo e emocional com intuito de desenvolver habilidades para ensino e aprendizagem (CUNHA, 2018, p. 60).

É necessário colocar o brincar em uma dimensão real que preenche o mundo das crianças com autismo, e não como uma atividade cultural. Há diversas maneiras de educar e entender que, ao unir o lúdico ao aprendizado poderá proporcionar relações novas e interessantes entre as crianças autistas e os saberes, com isso, a prática lúdica considera-se uma proposta pedagógica. Outra contribuição se dá, no fato, de analisar o comportamento do educando autista enquanto realiza atividades lúdicas (o brincar), pois será possível perceber características singulares, como suas etapas de desenvolvimento e aprendizagem. É importante ressaltar que a maneira de comunicação da brincadeira não se atribui a um pensamento, mas a um discurso ordenado com coerência e aspectos próprios com linguagem objetiva, desse modo, o brincar torna-se possível a constituição e o aumento de atribuições e saberes no que diz respeito aos planos do conhecimento e das interações sociais, o que resulta na obtenção de saberes no aprendizado. Relevante refletir sobre o papel social do educador em encarar as brincadeiras de uma perspectiva sociocultural, compreendendo seus benefícios e contribuições para o campo da Educação.

\section{4 - O LÚDICO NO DESENVOLVIMENTO DO AUTISTA}

O processo de construção do conhecimento dá-se respeitando a singularidade da criança com transtorno do espectro do autista, é essencial na função do professor respeitar, observar e conhecer seu discente que possui seu próprio tempo de evolução para desenvolver a comunicação social e a aprendizagem. Toda via, se faz necessário a participação de toda comunidade escolar e familiar para oportunizar esse aprendizado agregando apoio físico e humano (GÓMEZ, 2014).

Utilizar o lúdico como estratégia pedagógica não será uma tarefa fácil para o docente, pois deve ter clara consciência que o intuito é ser Lúdico e Educativo. Suas ações consistem, portanto, em agregar competência e segurança profissional para lidar com os discentes com necessidades educativas especiais. 
Essa modalidade de aprendizagem configura-se em pegar um brinquedo e brincar de um modo diferente, até mesmo o jogar, sendo uma estratégia para entrar na brincadeira do autista e seguir seu ritmo, o educador oportuniza o momento ideal para criar expectativas na criança, observar o momento de silenciar e permitir espaço ao autista, esse fluxo de conexão docente versus discente é um engajamento que consiste num desafio.

"Nenhuma aprendizagem é possível se não houver nenhuma base lúdica, se não houver prazer, se o espaço não é dado ao jogar, Jogar é conceitualmente diferente de jogo: o jogo é concreto, o jogar é o imprevisto" (GÓMEZ, 2014, p. 536).

Assim como, para a criança com transtorno do espectro do autismo, não se pode negligenciar o direito de brincar, a qualidade de vida, partindo do seu bem-estar físico, para que possa sentir-se feliz, obter prazer de viver, atribuindo para qualquer outro ser humano. O professor que interage com autistas, precisa investigar o que proporciona prazer ao seu aluno autista, partindo desta investigação possa introduzir a ludicidade para adquirir outros níveis de satisfação e enriquecer assim sua qualidade educacional. Os benefícios da utilização do lúdico em crianças com autismo podem facilmente ser percebidos quando os educandos deixam a insegurança dar espaço ao aprendizado de forma natural. Pode-se pontuar que, a relação entre docente e discente é muito importante no processo ensino-aprendizagem, principalmente no que se refere à utilização das práticas lúdicas para o desenvolvimento integral da criança com autismo.

Para Vygotsky (2007), o brincar se origina no imaginário da criança, onde desejos irrealizáveis podem se realizar, com a função de reduzir a tensão e, ao mesmo tempo, acomodar conflitos e frustrações da vida real. Já para Piaget (1985), representa uma fase no desenvolvimento intelectual, onde existe o domínio da assimilação sobre a acomodação, equilibrando a experiência passada. De acordo com Kishimoto (2011), necessário que o docente reflita nos pontos relevantes da concepção piagetiana por encontrar contribuições para o processo de ensino-aprendizagem, sendo assim, constatar que a construção do conhecimento não é estático, universal e atemporal, pois perpassa pelos processos de equilibração e reequilibração das estruturas cognitivas.

De acordo com Cunha (2018), o processo de construção do conhecimento do aluno com autismo demonstra similaridades com os demais alunos, mas, contradiz quando o assunto refere-se atenção principalmente se estiver atrelada realidade do professor, vale pontuar que, o aluno é protagonista de seu saber, ou seja, para promover o ensino e aprendizagem deve-se partir do campo de interesse do autista. Sendo o foco o instrumento da inteligência do nosso cérebro, o autista possui de modo surpreendente por atenta-se a detalhes que para muitas outras pessoas seria de difícil percepção, o que prejudica os autistas a partilhar de momentos de convívio social, pois o seu foco 
permanece em suas próprias experiências, com isso, surgem às dificuldades de estabelecer os vínculos sociais. Pertinente reflexão, dentro do contexto educacional o docente primeiramente deve conhecer seu aluno, investigar seu campo de interesse e, observar que dependendo da escolha do objeto de conhecimento pode gerar sentimento de desestimulo e desinteresse, logo, o objetivo pedagógico não será alcançado devido desatenção.

O Doutor em Educação, Antônio Eugênio Cunha (2018), afirma mediante estudo empírico que o processo de construção do saber perpassa por quatro estágios da aprendizagem, sendo acessível a todos os alunos incluindo os autistas, destaca que não deve ser aplicado com rigidez primordialmente no espectro autista, pois os sujeitos com autismo possuem suas particularidades e merecem ser respeitados. Nesta perspectiva torna-se imprescindível o preparo do professor para conduzir as singularidades em benefício do próprio aluno autista, nesse caso, o recurso metodológico utilizado como objeto do conhecimento assume o papel de condutor de atenção, tanto pode ser um objeto, um fato ou uma pessoa desde que atraía atenção do autista e seja o condutor da aprendizagem escolar.

Ao elaborar os quatros estágios da aprendizagem estruturados como: diretivo, autônomo, criativo e colaborativo (CUNHA, 2018, p.125 a 130).

- O estágio diretivo: temos a criança ainda pequena, não menciona faixa etária, no entanto, esse estágio a criança adquire conhecimento com sua inteligência, percebendo conforme sua vida psíquica se situa no mundo que a rodeia, pois viver é aprender. No processo educacional o professor ensina ao seu aluno nos ambientes educativos, a fim de estimular às primeiras aprendizagens, no cotidiano escolar que constitui a comunicação, a interação, a higiene pessoal, os trabalhos escolares, com a finalidade de alcançar a autonomia no campo pessoal, social e escolar. Dentro das condições do aluno com autismo, respeitando suas particularidades, neste processo de aprendizagem inicial ocorre à transição de um estágio para o outro, sendo que, o próximo estágio corresponde à autonomia.

- No estágio autônomo: o aprendiz possui habilidades de iniciativa própria, realiza suas escolhas com autonomia, as relações entre professor e aluno estabelecem o sucesso na construção das aprendizagens. Neste estágio despertar-se a curiosidade epistemológica onde o protagonista apropria-se do seu saber para formular novos saberes. No contexto da educação inclusiva, torna-se essencial o comprometimento do docente, pois o fator preponderante está na conquista da independência intelectual e operacional do aluno, destaca-se tamanho desafio demasiado esforço e paciência, porém os resultados surgiram.

- O estágio criativo: o próprio educando com autismo busca mecanismos de modo criativo para aprender. A aprendizagem torna-se transformadora por ser vivenciada de forma consciente pelo autista que faz uso das funções cognitivas transpondo novas formas de realizar as tarefas e manusear os materiais. No 
contexto educacional não há necessidade de estar sempre criando algo novo, no entanto, permitir que seja de caráter inédito, o professor precisa refletir sobre essa possibilidade de aprendizagem notável ruptura nos padrões de ensino, pois o educando com necessidades educativas especiais fórmula de modo criativo aquisição do conhecimento.

- No estágio colaborativo: descreve alunos com extrema competência e habilidades em determinado campo de conhecimento, como também, alunos cuja habilidade consiste no conteúdo curricular ensinado pelo docente, ambos fazem parte da educação especial e do ensino regular. Logo, são características específicas do estágio colaborativo quando o educando munido pelo domínio dos conteúdos pode assumir o papel de cooperador auxiliando seus colegas que estejam com maiores dificuldades, mas, é necessário ressaltar que a linguagem própria do autista e a maneira de ensinar será diferente do professor.

$\mathrm{Na}$ atual sociedade contemporânea é fato que as informações circulam cada vez mais rápido devido o mundo globalizado e tecnológico, o aluno com espectro autista apropria-se das tecnologias digitais com proficiência devido às possibilidades nas redes de conexões, até que algo desperte sua atenção e interesse. É notório que, dentro do universo escolar cabe ao docente identificar as competências e habilidades, para desenvolver um ensino colaborativo introduzindo produções individuais e as coletivas, com isso, promover a socialização e aquisição do saber. Segundo Cunha (2018), qualquer aluno inclusive o aluno com espectro do autismo aprende melhor quando the é proporcionado uma educação qualificada mediante o desenvolvimento dos estágios diretivo, autônomo, criativo e colaborativo. O autor afirma que o ato colaborativo conduz o sujeito para socialização, processando-se por intermédio da comunicação de crenças, valores e cultura, sendo indispensável para a inclusão.

Faz-se necessário que o docente estabeleça relação dialógica com o discente com transtorno do espectro do autismo, e neste processo dialógico ocorra às rupturas de paradigmas, pois o aprendiz aprende de modo diferente, sendo assim, diferente é o modo como o professor ensina (CUNHA, 2018, p. 139).

Segundo Kishimoto (2011), menciona conceitos essenciais que estrutura o trabalho pedagógico, ao propiciar relevante contribuição do lúdico para o campo da Educação. Situa uma perspectiva de construção do conhecimento partindo da criança com o uso do brinquedo e os jogos, com isso, o importante é conhecer, de fato, quem é o protagonista da construção do saber, partindo dessa reflexão, o docente precisa investigar, observar e compreender as amplitudes e particularidades do discente autista para propor-Ihe uma proposta educacional que atenda suas necessidades educacionais especiais.

É necessário que o docente tenha clareza que no processo de desenvolvimento ensinoaprendizagem onde o conhecimento é construído mediante o uso dos brinquedos, jogos 
e as brincadeiras o aprendiz percorre um caminho mediante proposta das práticas lúdicas relacionada com o ensino e aprendizagem. Assim como, evidencia-se que dentro desse processo pode acontecer que o modo como o autista aprende, também ocorre o não aprendizado ocasionado pelo desinteresse. De acordo com Cunha (2018), é possível que o discente com autismo não aprenda corretamente o que lhe foi ensinado, porém, deve-se analisar que foi trabalhado a interação, a comunicação, a cognição, os movimentos e outras habilidades.

O professor Whitman (2015), apresenta as contribuições obtidas com a terapia lúdica aplicada em crianças autistas, fica claro constatar que o lúdico abrange também a Psicologia outra área do conhecimento. A abordagem considera as brincadeiras essenciais para o desenvolvimento de todas as crianças, entretanto, particularmente direcionado aqui à criança autista onde a brincadeira é encarada como algo desafiador e frustrante, contudo, a ludicidade continua ser um recurso de muito valor, pois auxiliar no desenvolvimento sensório-motor, cognitivo, linguístico, social e emocional. A terapia lúdica inicia os procedimentos lúdicos como algo reflexivo e simples, pouco a pouco vai atribuindo uma intencionalidade, pois a brincadeira proporciona a criança momentos para explorar e aprender em seu ambiente escolar, tais como: meios de se aparecer, conhecer diferentes sons, que gosto tem e como responder.

Esses procedimentos entre outros fazem parte do contexto educacional de toda criança, incluindo as crianças autistas. Em um ritmo diferenciado o autista, no brincar, aprender a notar a mudança e a permanência na organização do ambiente, sobre relacionar causa e efeito e como manusear determinados objetos. Com atividades divertidas as crianças autistas podem desenvolver habilidades, competências e potenciais, podem também, aprender mediante brincadeiras com objetos, jogos imaginativos e jogos sociais, sendo necessário planejar, organizar e estruturar a proposta lúdica, pois a criança com espectro do autismo pode assimilar respostas de atenção, imitação, percepção motora e da linguagem.

No executar a prática lúdica quanto melhor for estruturada a proposta, qualifica o apoio oferecido na busca da motivação e desempenho da criança autista, também é importante a organização dos espaços e os materiais lúdicos para combater a distração dos envolvidos na proposta, outro ponto relevante são as rotinas que proporciona segurança ao ensino e aprendizado (WHITMAN, p. 192, 2015).

De acordo com Cunha (2018), ao descrever que no cotidiano escolar pode considerar normal o comportamento do aluno autista quando suas manifestações são de irritação, fugir e desviar, justamente para não realizar a proposta pedagógica, é fundamental que o professor não incentive tais manifestações, mas que faça as devidas intervenções de forma lúdica, atribuindo calma e afeto. É bom ressaltar, da importância do educador 
conhecer seu aluno autista, ter um olhar atento às mudanças de comportamento para investigar e compreender o que está ocasionando essa conduta.

Em virtude de reflexão, como é relevante que a proposta pedagógica esteja estruturada para promover o ensino e aprendizado da criança com transtorno do espectro do autismo, ainda que o recurso seja mediante práticas lúdicas, uma vez que, o docente precisa ter clareza das singularidades e das dificuldades sensoriais, motores, cognitivos, de linguagem e social. O autor Whitman (2015), considera benéfico a ponto de destacar três características com intuito de auxiliar a prática pedagógica, são elas: objetivos claramente definidos, métodos para realizar a intervenção e os materiais didáticos, tudo isso, permite um viés para correlacionar com a ludicidade. Enfatizar que incluir os jogos e as brincadeiras no contexto dessa concepção corresponde às intervenções estruturadas educacionais, isto é, especificar qual habilidade, competência e potencialidade foram adquiridos pelo autista.

A luz da perspectiva psicopedagógico que descreve a construção do conhecimento e do saber do discente com autismo, sendo este, protagonista do seu conhecimento, por intermédio do uso de brinquedos, brincadeiras e jogos, numa intervenção que qualifica o enfoque pedagógico, pois articula no processo de aprendizagem os diferentes eixos de estruturação, tais como: afetivos, cognitivos, motores e sociais. Conforme a necessidade educacional específica do aluno com transtorno do espectro do autismo relevante que o recurso pedagógico por incluir o lúdico neste processo de construção do saber, compreende sua contribuição de facilitar demasiado conhecimento que valerá por muitos anos (KISHIMOTO, 2011, p. 121 e 122).

A busca pelo êxito da aquisição do saber do discente autista inicia-se na análise dos aspectos que fazem parte dos processos de escolarização, de modo alargar o que se referem os brinquedos, brincadeiras e jogos, enquanto objetos estruturadores do conhecimento e do saber. Para Kishimoto (2011), para o primeiro aspecto fundamental é compreender que os brinquedos, as brincadeiras e os jogos não transmitem o saber pronto e acabado, pelo contrário, o inegável potencial pedagógico mediante os objetos para realizar a intervenção estruturada. O próximo aspecto introduz o objeto como algo dinâmico e seu uso não será igual, partindo do pressuposto que cada autista é um autista que precisa ser respeitada suas particularidades. O último aspecto esclarece que é preciso observar que mesmo inserindo o objeto pode acontecer do aluno não alcançar o objetivo proposto com o objeto estruturado de facilitar o processo de construção do conhecimento, nesta situação faz-se necessário identificar com precisão para realizar a intervenção adequada aponto de retomar a ludicidade.

Neste contexto, o olhar observador do docente em prol da aprendizagem torna-se indispensável, cuja percepção é capaz de identificar os pequenos detalhes que corroborar na modificação da estratégia pedagógica, no entanto, sem mudar objeto, 
desafiadora, porém cabe ao docente identificar qual objeto é capaz de corresponder positivamente com aprendizagem, sendo assim, qual objeto enquadra-se no perfil do discente autista? Afinal, o objetivo é inserir o jogo, a brincadeira e o brinquedo no processo de aquisição do saber.

Obviamente, faz parte do universo da ludicidade acentuar alguns sintomas que desperta nos envolvidos como o bom humor, a positividade, a alegria, o desafio, a disposição, a criatividade, etc., são características envolvidas nas práticas lúdicas, visto que, as relações entre docente/discente e discente/discente não têm de ser passivo muito menos calmo conforme este dinâmico processo de construção do conhecimento, tanto quão complexa por esperar ver o docente brincando com seus discentes numa relação onde o fator determinante é o processo do conhecimento mediante contribuição do lúdico.

\section{5 - CONSIDERAÇÕES FINAIS}

O presente estudo apontou o lúdico no processo de ensino e aprendizagem, abordou as contribuições no desenvolvimento da criança com autismo, como também, contribuiu com os conhecimentos acadêmicos que se estendem ao campo profissional.

Essa pesquisa impulsionar a mergulhar em reflexões sobre a necessidade da utilização de um ensino diferenciado para crianças com necessidades educacionais especificas (no caso aqui abordado: Autismo), a fim de que, atingir o objetivo maior que é o desenvolvimento integral da criança autista.

O educando pertencente à sociedade contemporânea precisa ser estimulado a se envolver no processo ensino-aprendizagem, levando em conta as fases de desenvolvimento da teoria de Piaget, e considerando os estágios da aprendizagem estruturados em Diretivo, Autônomo, Criativo e Colaborativo pelo autor Eugênio Cunha (2018), por afirmar que o docente que busca observar para conhecer seu alunado consegue realizar as devidas intervenções conforme suas particularidades autísticas, sendo que, a proposta pedagógica consiste em utilizar com maior frequência no cotidiano escolar as práticas lúdicas, cujas contribuições envolve os jogos em práticas exploratórias e involuntárias inicialmente, propicia experiência motoras-visuais e consequentemente sensório-motoras, a partir do contato do jogo simbólico até o aperfeiçoamento da linguagem onde o pensamento começa a se desenvolver, com isso, corroborar para o processo em desenvolvimento físico e intelectual do discente.

No ato de Brincar, a criança se torna autor ativo do seu processo de aprendizagem, pois vivencia a construção dos saberes e consegue expressar emoções e desejos, desenvolvese mais seguro dentro do seu próprio tempo, isto é, deve-se considerar a criança autista um ser singular que precisa ser respeitado, necessário neste processo de ensino e 
aprendizagem estabelecer interação social, ainda que, possua suas dificuldades e favorecer comunicação verbal e social.

Em função disso, concluo que o lúdico facilita a trajetória do processo de desenvolvimento da comunicação verbal e social, pois brincando, a criança conhece a realidade externa identifica os vínculos estabelecidos em constante interação com o mundo, desse modo, a construção do conhecimento de mundo é interiorizada.

Enfatizo que esta é uma característica fundamental da ludicidade, uma potente ferramenta facilitadora do processo ensino/aprendizagem e, como recurso metodológico qualifica a didática pedagógica com o uso nos diferentes ambientes escolares. Desejo que os frutos desta pesquisa possam alcançar e conscientizar demais profissionais do campo da Educação. 


\section{BIBLIOGRAFIA}

ALMEIDA, Paulo Nunes de. Educação Lúdica: técnicas e jogos Pedagógicos. São Paulo: Loyola, 1987.

BROUGÈRE, Giles. Jogo e Educação. Porto Alegre: Artes Médicas, 1998.

CAMARGO Jr, Walter et al. Transtornos Invasivos do desenvolvimento: $3^{\circ}$ milênio. $3^{\text {a }}$ Ed. - Brasília: Secretária de Direitos Humanos. Subsecretaria Nacional de Promoção dos Direitos da Pessoa com Deficiência, 2010.

COLL, César, MARCHESI, Álvaro, PALACIOS, Jesús. Desenvolvimento psicológico e educação: transtornos do desenvolvimento e necessidades educativas especiais. $2^{a}$ ed., Porto Alegre: Artmed, 2004.

CUNHA, N. H. S. Brinquedoteca - Um mergulho no brincar. $4^{\text {a }}$ ed. São Paulo: Aquariana, 2007.

CUNHA, Eugênio. Autismo na escola: um jeito diferente de aprender, um jeito diferente de ensinar. $5^{\mathrm{a}}$ ed. Rio de Janeiro, 2018.

DONVAN, John, ZUCKER, Caren. Outra sintonia: a história do autismo. 1 ed. São Paulo: Companhia das Letras, 2017.

GOMES, C. G. Santos, SILVEIRA, A. Dutra. Ensino de Habilidades Básicas para pessoas com autismo. $1^{\mathrm{a}}$ ed. Curitiba: Appris, 2016.

GÓMEZ, Ana M. Salgado, TERÁN, Nora Espinosa. Transtornos de aprendizagem e autismo. Editora: Cultura, 2014.

KISHIMOTO, Tizuko Morchida. Jogos Infantis: o jogo, a criança e a educação. 15. a ed. Petrópolis: Vozes, 2009.

KISHIMOTO, Tizuko Morchida. Jogo, Brinquedo, brincadeira e a educação. 14 ed. São Paulo: Cortez, 2011.

SANTOS, Santa Marli Pires dos (Org.). O lúdico na formação do educador. Petrópolis, RJ: Vozes, 1997.

VYGOTSKY, Lev Semionovitch. A formação Social da mente: o desenvolvimento dos processos psicológicos superiores. São Paulo: Martins Fontes, 1994.

WHITMAN, Thomas L. O desenvolvimento do Autismo: social, cognitivo, linguístico, sensório-motor e perspectivas biológicas. São Paulo: M.Books do Brasil, 2015 